University of Nebraska - Lincoln

DigitalCommons@University of Nebraska - Lincoln

Faculty Publications, Department of Psychology

Psychology, Department of

2009

\title{
The dynamics of development: Challenges for Bayesian rationality
}

Nils Straubinger

Max Planck Institute for Human Development, straubinger@mpib-berlin.mpg.de

Edward T. Cokely

Max Planck Institute for Human Development, cokely@mpib-berlin.mpg.de

Jeffrey R. Stevens

University of Nebraska-Lincoln, jstevens5@unl.edu

Follow this and additional works at: https://digitalcommons.unl.edu/psychfacpub

Part of the Psychiatry and Psychology Commons

Straubinger, Nils; Cokely, Edward T.; and Stevens, Jeffrey R., "The dynamics of development: Challenges for Bayesian rationality" (2009). Faculty Publications, Department of Psychology. 522.

https://digitalcommons.unl.edu/psychfacpub/522

This Article is brought to you for free and open access by the Psychology, Department of at DigitalCommons@University of Nebraska - Lincoln. It has been accepted for inclusion in Faculty Publications, Department of Psychology by an authorized administrator of DigitalCommons@University of Nebraska - Lincoln. 
they do not adecuately account for how variation infuences a Bayesian rational analysis of reasoning. Anderson (1991a) and others have pointed out that perhaps the major potential limitation, the "Achilles heel," of rational analysis would be computational constraints that are too complex or arbitrary. We argue that our understanding of the mechanisms of change in reasoning can help us specify computational limitations for probabilistic modeling and assess whether a single model can capture the complexities of reasoning.

Many important aspects of cognition change over the lifespan, and reasoning is no exception (Baltes et al. 1999). According to Piaget, both logical reasoning and probabilistic reasoning emerge from adolescence to young adiuthood at the highest stage of cognitive development (Piaget \& Inhelder 1975). Subsequent research, however, has cualified these findings, showing that younger children understand aspects of such reasoning (Falk \& Wilkening 1998; Galotti et al. 1997). Furthermore, reasoning continues to develop during adulthood with performance ix spectio domains increasing as individuals gain reasoning knowledge and expertise (Ericsson \& Lehmann 1996; Sternherg 1999). Yet, overall across the adult lifespan, abstract reasoning (measured by intelligence tests) declines with age (Verhaeghen $\&$ Salthouse 1997). Thus, reasoning is a dynamic aspect of cognition that varies with age and experience and results from the interplay of hiological processes (e.g., hrain maturation) and enculturation (e.g., education) (Baltes et al. 1999).

A developmental perspective may inform Bayesian rational analysis by specifying computational limitations of the cognitive system. An important limitation faced by the human cognitive system is working memory capacity - a key determinant of reasoning performance (Kyllonen \& Christal 1990). Like other cognitive capacities, working memory systematically changes across the lifespan by steadily increasing during childhood (Conlin et al. 2005) and declining across adulthood (Verhaeghen $\&$ Salthouse 1997). Working memory, therefore, poses a dynamic constraint on the rational analysis of reasoning.

\section{The dynamics of development: Challenges for Bayesian rationality}

doi: $10.1017 / \mathrm{S} 0140525 \times 09000491$

\author{
Nils Straubinger, Edward T. Cokely, and Jeffrey R. Stevens \\ Center for Adaptive Behavior and Cognition, Max Planck Institute for Human \\ Development, Berlin, 14195, Germany. \\ straubinger@mpib-berlin.mpg.de \\ cokely@mpib-berlin.mpg.de \\ jstevens@mpib-berlin.mpg.de \\ http://www-abc.mpib-berlin.mpg.de/users/jstevens /
}

\begin{abstract}
Oaksford \& Chater (O\&C) focus on patterns of typical ardult reasoning from a probabilistic perspective. We discuss implications of extending the probahilistic aproach to lifespan development, considering the role of working memory, strategy use, and expertise. Explaining variations in human reasoning poses a challenge to Bayesian rational analysis, as it requires integrating knowledge about cognitive processes.
\end{abstract}

Bayesian rationality highlights the remarkahle successes rather' than failures of human reasoning by recasting seemingly erroneous reasoning in logical tasks using a probabilistic approach. However, in their book Bayesian Rationality (Oaksford \& Chater 2007, henceforth BR), Oaksford \& Chater (O\&C) draw a rather static picture of human reasoning by focusing on typical patterns of responses from adults. We propose a more dynamic perspective, which considers that reasoning systematically varies within individuals over the lifespan (Howe \& Rahinowitz 1996; Markovits \& Barrouillet 2002) and hetween individuals with different levels of knowledge and expertise (Ericsson et al. 2006). Although O\&C; acknowledge the importance of considering reasoning data on individual differences (BR, p. 288) and on information processing capacities (p. 290),
Although O\&C are currently silent on the role of developmental changes in working memory and reasoning, they do note that individuals with higher working memory capacities tend to exhibit more logical reasoning. T'o illustrate, in the Wason selection task, a subgroup of individuals (ca. 10\%) consistently chooses the logically correct combination of cards, indicating that although most seem to adopt a probahilistic model, others clearly do not. O\&C suggest that this variation in hehavior primarily refoets delberative strategy we and educational training) differences. which are "not indicative of individual differences in the nature of the fundamental principles of human reasoning" $(B R$, p. 288$)$. This claim seems problematic given what we know ahout the interplay between strategy use, training, and basic cognitive mechanisms. Of course, cognitive capacities can constrain the strategies that people use; however, spectic strategy ase and training may shape the basio cognitive mechanisms, as well. Differences in memory strategies (e.g., rehearsal, chunking) can also alter basic mechanisms of working memory capacity and its relationship to cognitive performance (Cokely et al. 2006). In addition, hoth extensive practhe with pecific strateges and the accuisition of knowledge and expertise dramatically expand working memory (Ericsson $\&$ Kintsch 1995). Indeed, as training changes deliberative strategies to automatic processes, the cortex can undergo functional neuroanatomical reorganization (Dick et al. 2006). Thus, it is possible that deliberative strateg use and training may infuence reasoning precisely because they alter underlying cognitive mechanisms such as working memory. Given the complex relationship between strategies, training, and cognitive mechanisms, it seems premature to dismiss individual differences in strategy use as not fundamental to reasoning. A comprehensive model of human reasoning must account for these differences.

Vaxiation in buman reasoning has proven difficult to capture for probahilistic models (Shultz 2007), although recent research 
has made some progress applying prohahilistic models to individual differences (e.g., category learning; Navarro et al. 2006) and cognitive development (e.g., causal reasoning: Sohel et al. 2004). This work represents a step in the right direction: however', we expect that no single model can predict reasoning performance equally well across age groups and levels of experience. Indeed, systematic variations in peoples hehavior sıggest that severd different models (or modifications of a given model) may be required to explain developing behavior (Shultz 2007). Nevertheless, investigating differences hetween the models across age groups and skill levels may help us to understand more exactly "what differs" between and "what develops" within individuals.

In closing, we must emphasize O\&C's comment that probahilistic models are often only functional level theories that should not he confused with algorithmic level theories (process models). Brighton and Gigerenzer (2008) have pointed out in their discussion of the limits of Bayesian models of cognition that the question of why the human mind does what it does (functional level) cannot he separated from the question of how the human mind does it (algorithmic level). Therefore, it is crucial that future Bayesian rational analyses specify how exactly their functional level models constrain theorizing about cognitive processes. This issue is especially relevant as the data connecting development, expertise, working memory, and reasoning inply that multiple strategies (and therefore processes) are at play. Though Bayesian rationality seems to provide a functional level account of prototypical adult reasoning, the development of cognitive capacities and expertise remains underappreciated.

\section{ACKNOWLEDGMENTS}

Preparation of this commentary was supported in part by a stipend from the International Max Planck Research School LIFE to NS. We are gratefil to Henrik Olsson for comments on a previous draft. 